12 - ARTIGO ORIGINAL

\title{
Emprego da submucosa de intestino delgado na correção de estenose esofágica em cães ${ }^{1}$
}

Small intestinal submucosa for reconstruction of esophageal stricture in a dog model

\author{
Zacarias Alves de Souza Filho ${ }^{2}$, Fernando Hintz Greca ${ }^{3}$, João Ricardo Duda ${ }^{4}$, \\ Guilherme Zicarelli Cravo ${ }^{4}$, Sérgio Ossamu Ioshii ${ }^{5}$
}

1.Trabalho realizado na Disciplina de Técnica Operatória e Cirurgia Experimental do Centro de Ciências Biológicas e da Saúde (CCBS) da Pontifícia Universidade Católica do Paraná (PUC-PR).

2. Prof. Titular de Clínica Cirúrgica e da Disciplina de Técnica Operatória e Cirurgia Experimental da PUCPR e da UFPR.

3. Prof. Titular e Coordenador da Disciplina de Técnica Operatória e Cirurgia Experimental da PUC-PR e Prof. Adjunto da Disciplina de Cirurgia Geral da UFPR .

4. Alunos Curso de Medicina: Monitores da Disciplina de Técnica Operatória e Cirurgia Experimental da PUC-PR.

5. Prof. Adjunto de Anatomia Patológica das Faculdades de Medicina da PUC-PR e UFPR.

\section{RESUMO}

OBJETIVO: Pesquisar a eficácia da Submucosa de lntestino Delgado (SID) porcina na correção de estenoses esofágicas cervicais em cães.

MÉTODOS: Para produzir estenose, 12 animais foram submetidos a ressecções de porção elíptica de 3,5X2,0 cm, na parede anterior do esôfago cervical, suturado por pontos de fio de algodão. $O$ processo evolui por 90 dias, atingindo a estenose desejada e comprovada por esofagograma. Na sequiência, a lesão cicatricial produzida foi ressecada e substituída por enxerto de SID. Transcorridos 2 meses os animais foram submetidos a novo esofagograma. Aferiu-se então a largura esofágica (nas porções proximal e média do esôfago cervical) após a realização da estenose e pós-correção. Os animais foram submetidos a eutanásia, ao $60^{\circ}$ dia de pós-correção, e à necropsia os esôfagos foram retirados e enviados ao laboratório de Anatomia Patológica.

RESULTADOS: Não houve fístula ou infecção. Ocorreram reepitelização completa da mucosa, discreta reação infamatória e neovascularização moderada. A luz esofágica foi ampliada em $70 \%$ dos animais $(43 \% \pm 13 \%$ em média $)(p=0,2135)$. A medida da porção proximal, passou de $0,76 \mathrm{~cm}$ para $0,95 \mathrm{~cm}$ em média $(\mathrm{p}=0,02)$. Não houve alteração significativa em relação a porção medial.

CONCLUSÃO: A SID demonstrou ser, no cão, enxerto eficaz para correção de estenoses esofágicas, integrando-se nitidamente à sua parede e substituindo-a de forma adequada.

Descritores: Esôfago. Estenose. Submucosa de intestino delgado. 
PURPOSE: The objective of the present study is evaluating the efficiency of porcine Small Intestinal Submucosa (SIS) as graft in the managemant of stenotic cervical esophagus lesions in dogs.

METHODS: Twelve dogs were submitted to resection of an eliptic $(3,5 \mathrm{X} 2,0 \mathrm{~cm})$ portion of the anterior esophagus wall followed by cotton suture repair. Three months later stenosis were confirmed by esophagogram. Next, scar tissue formed was ressected followed by SIS patch placement. Two months after the procedure new esophagogram was performed. Esophageal width was measured at the proximal and middle third portions, before and after the SIS patch placement. Animals were sacrified, and esophagus were sent for histological examinations.

RESULTS: No fistula or infection were found. Microscopic analysis revealed complete mucous membrane regeneration, discrete inflamatory reaction and moderate vascular proliferation. Esophageal width was enlarged in $70 \%$ of studied animals $(43 \% \pm 13 \%)(\mathrm{p}=$ 0,2135 ). Proximal measurement increased from $0,76 \mathrm{~cm}$ to $0,95 \mathrm{~cm}$; no significantly change occurred at the medial portion.

CONCLUSION: SIS proved to be reliable graft reapair for canine esophageal stenotic lesions. It integrates to the esophageal wall and adequately replaces it.

Key words: Injuries. Esophagus. Submucosa.

\section{Introdução}

São diversas as causas de estenose esofágica, destacando-se o refluxo gastro-esofágico, as colagenoses e a ingestão de substâncias cáusticas ${ }^{1}$. Muitas vezes a estenose é uma complicação do próprio tratamento das lesões do esôfago, uma vez que a tensão na linha de sutura num órgão sem serosa com frequiência propicía a formação de fístulas e estenoses 2,3,4,5. Em muitas situações o paciente apresenta-se clinicamente instável, havendo a necessidade de uma terapêutica rápida e de fácil execução. Em lesões diagnosticadas tardiamente, certo grau de necrose tecidual pode já estar instalado e extenso debridamento pode ser necessário, causando mais perda tecidual ${ }^{2,3}$. Ressecção segmentar e anastomose término-terminal primária são condutas de exceção e requerem extensa dissecção e mobilização do esôfago ${ }^{1,2,3,4}$. O uso de exclusão esofágica predispõe à necessidade de gastrostomia, esofagostomia e/ou alimentação parenteral e está relacionado a elevado coeficiente de mortalidade ${ }^{1,2,7,8,9}$. Há uma diversidade substancial de condutas em relação ao tratamento: as estenoses pépticas são mais comumente manejadas através de dilatações endoscópicas ${ }^{1}$. Para as demais situações, surgem as opções de reconstrução com segmentos pediculados de cólon transverso ${ }^{10}$ ou jejuno ${ }^{11}$. São também clássicas as interposições de porções do intestino como o estômago, o cólon e o jejuno ${ }^{12}$. A submucosa de intestino delgado porcina (SID) é uma matriz colágena extracelular ${ }^{13}$ que vem sendo utilizada com bons resultados no reparo de tecidos vasculares ${ }^{13}$, do aparelho urinário ${ }^{14,15,16}$, da parede abdominal ${ }^{17}$, cartilagens ${ }^{18}$, entre outros. Segundo diversos autores, a SID apresenta características próprias que proporcionam a ela vantagens em relação aos demais enxertos biológicos. Dentre elas, destacam-se os glicosaminoglicanos, que conferem bioatividade a diversas citocinas e fatores de crescimento que atuam na revascularização e cicatrização de ferimentos ${ }^{19}$. O fator de crescimento do endotélio -"VEGF"- induz a formação de estruturas similares a capilares fenestrados na matriz de fibrina, promovendo 
uma neovascularização local ${ }^{20}$. O "PDGF" (fator de crescimento derivado de plaquetas) atua na proliferação fibroblástica ${ }^{21,22}$ e é suplementado pela imediata deposição de fibronectina, responsável primária pelo recrutamento e pela retenção das células do hospedeiro que povoarão o local da ferida ${ }^{23,24}$. Com relação à resposta imune da SID, observou-se que esta é restrita aos linfócitos T-helper 2, que ativam interleucinas nãoinflamatórias. Estas, por sua vez, produzem anticorpos não ligados a complementos. Desta forma, não há uma rejeição do tecido implantado ${ }^{25,26}$. A resistência à infecção está provavelmente correlacionada ao rico e rápido desenvolvimento de suprimento sangüíneo 27. A SID já foi utilizada como enxerto no reparo de lesões esofágicas em cães. Apresentou baixo grau de estenose, epitelização completa, organização das fibras musculares e moderada vascularização ${ }^{28,29}$. Não há relatos na literatura referindo-se ao seu uso com a finalidade de correção de estenose esofágica. As promissoras características da membrana submucosa, os bons resultados descritos na literatura em relação à sua aplicação, a morbidade das estenoses esofágicas, bem como a ausência de um consenso em relação ao manejo destas lesões nos motivaram a pesquisar, experimentalmente no cão, a eficácia da SID porcina como enxerto parcial na correção das estenoses do esôfago.

\section{Métodos}

\section{A amostra}

Utilizaram-se 12 cães mestiços, entre estes haviam sete machos e cinco fêmeas, com peso mais próximo possível de $15 \mathrm{Kg}$, obtidos junto ao biotério da PUC-PR. Os animais foram mantidos em ambiente adequado, com temperatura e luminosidade naturais e alimentados com ração canina e água ad libitum. O experimento foi realizado no laboratório de Técnica Operatória e Cirurgia Experimental da própria Universidade. O estudo foi aprovado pelo Comitê de Ética em Pesquisa em Animais (CEPA) do Centro de Ciências Biológicas e da Saúde (CCBS) da Pontifícia Universidade Católica do Paraná (PUC-PR).

\section{O enxerto}

O fragmento de submucosa de intestino delgado de suíno é obtido da seguinte maneira: Uma porção do jejuno é removida no abatedouro nos 10 minutos após a morte do animal e imediatamente colocada em solução salina a $0,9 \%$. O segmento intestinal é inicialmente invertido e a túnica mucosa é removida mecanicamente através de um aparelho no próprio abatedouro; inverte-se novamente o alça intestinal para a remoção da túnica seromuscular através do mesmo aparelho. Uma fina membrana translúcida, que constitui a submucosa é assim obtida. Procede-se a irrigação exaustiva do tecido com solução salina isotônica e conserva-se em solução de sulfato de neomicina $10 \%{ }^{30}$, em geladeira por no máximo 30 dias.

O procedimento 
Anestesia: Induzida através de xilazina $1 \mathrm{mg} / \mathrm{kg}$ e mantida com tiopental sódico, $15 \mathrm{mg} / \mathrm{kg}$ via endovenosa, diluído em água destilada; os animais foram mantidos sob ventilação espontânea.

Realizou-se cervicotomia paratraqueal esquerda de $8 \mathrm{~cm}$. O esôfago foi exposto e de sua parede anterior, ressecada uma porção elíptica de aproximadamente $3,5 \mathrm{~cm}$ de comprimento, correspondendo a um terço da circunferência total do órgão e abrangendo todas as camadas (Figura 1). A fim de conferir estenose significativa ao órgão, reparou-se a lesão com sutura estenosante contínua com fio de algodão $3.0 \mathrm{em}$ dois planos: mucoso e muscular. (Figura 2) Decorridos 3 meses, realizou-se esofagograma com finalidade de comprovar a estenose (Figura 4). Nesta ocasião, foram tomadas as medidas da largura das porções proximal e média do esôfago cervical. Em seguida, os cães foram novamente conduzidos ao centro cirúrgico para correção da estenose. Para isto, ressecou-se a área de fibrose onde fora realizada a sutura. A reconstrução do órgão foi feita com enxerto composto de dois folhetos de SID de $3 \times 4 \mathrm{~cm}$, que foi suturado de forma contínua às camadas mucosa e submucosa do esôfago com fio de Monocryl ${ }^{\circledR} 4.0$ (Figura 3). Suturou-se a pele com fio Mononylon ${ }^{\circledR}$ 3.0. Dois meses após, novo esofagograma foi realizado para comparação com aquele realizado ao tempo da estenose. Mediu-se também a largura esofágica em suas porções proximal e média (Figura 4).

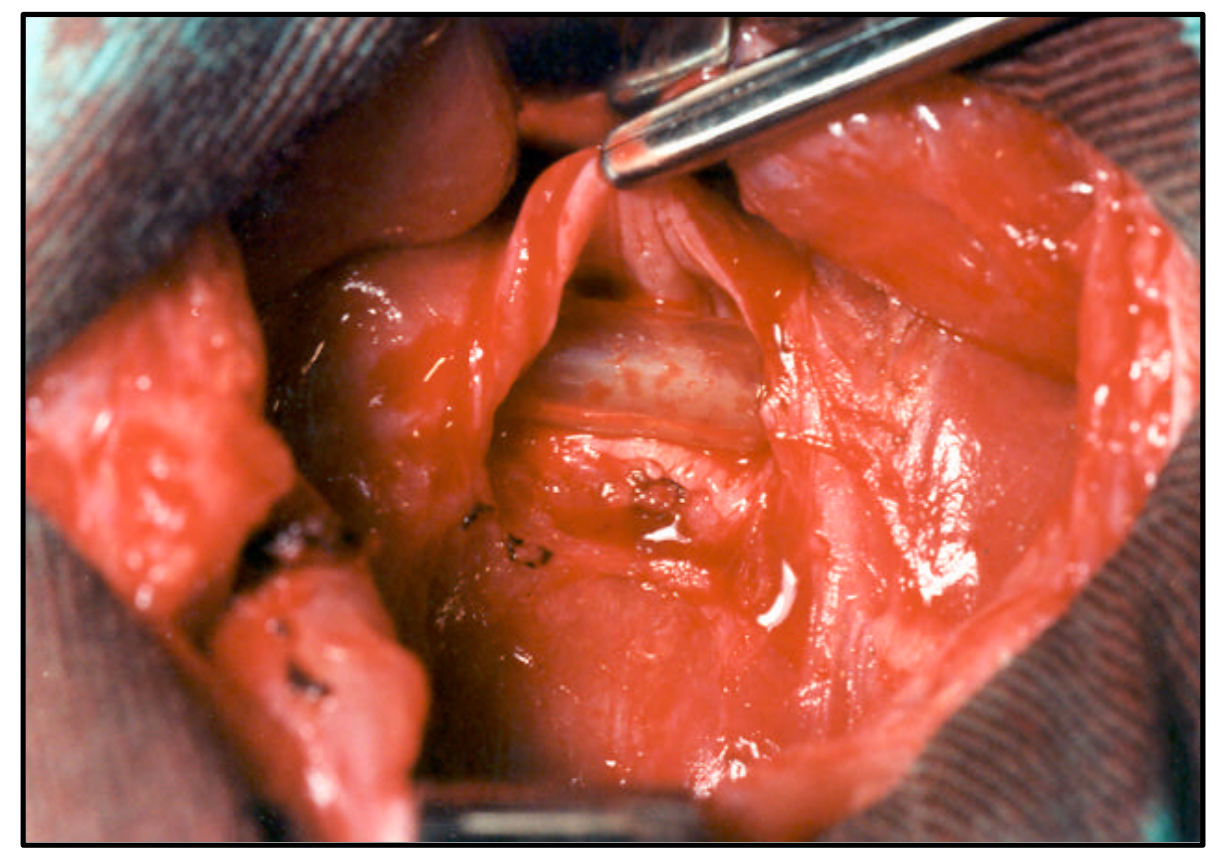

FIGURA 1 - Extensa ressecção de tecido esofágico. 


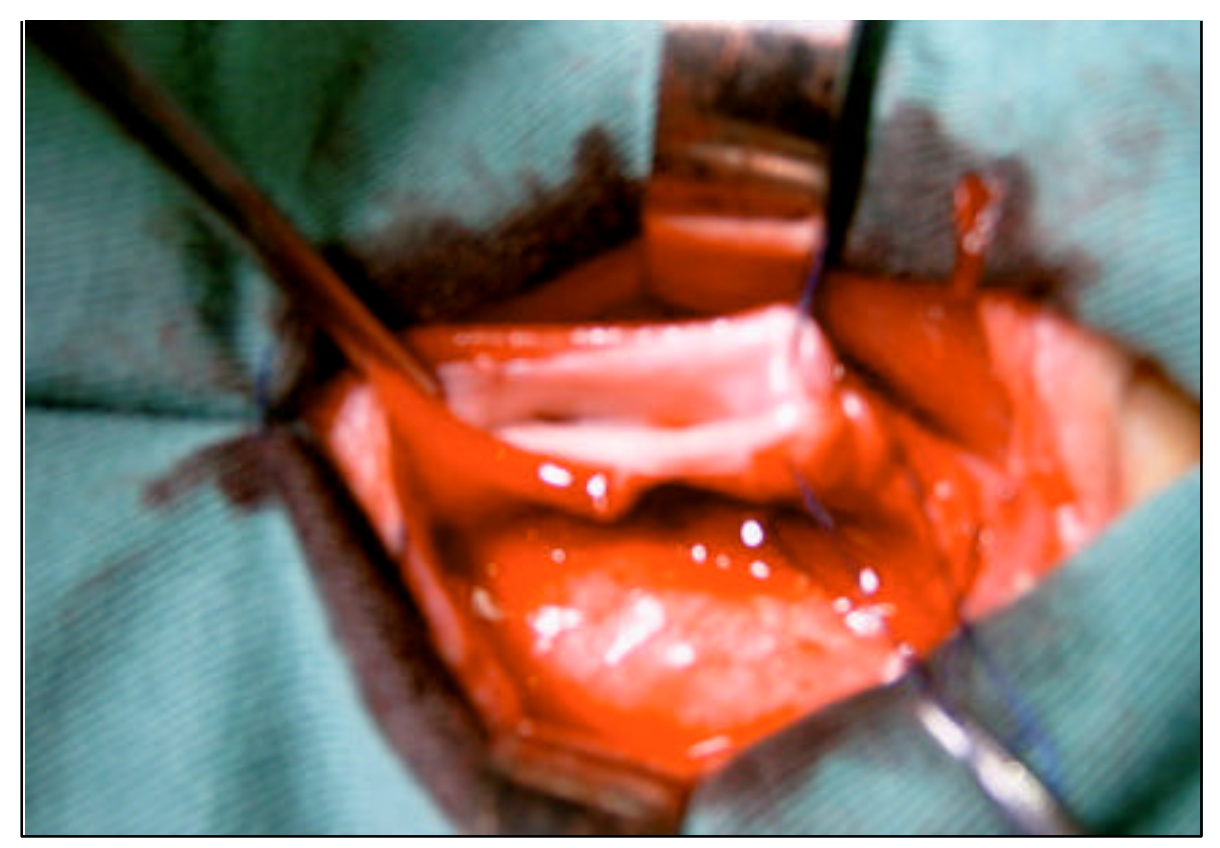

FIGURA 2 - Indução da estenose com sutura contínua com fio de algodão 3-0.

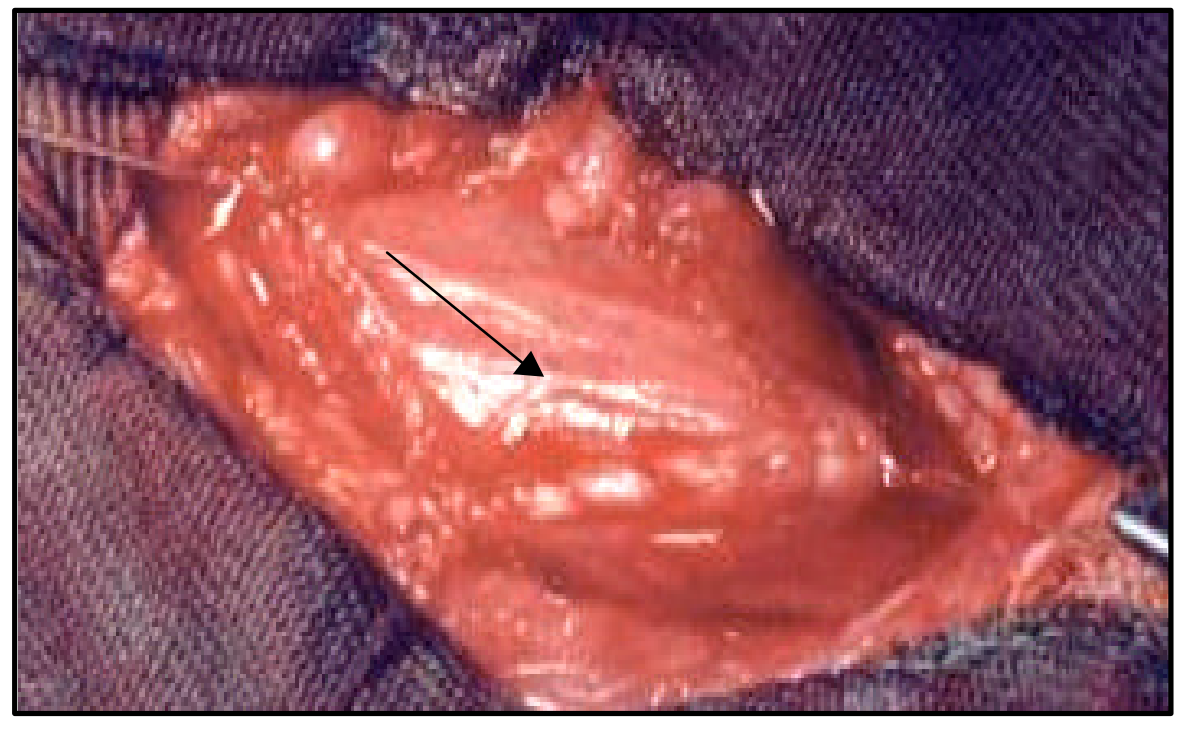

FIGURA 3 - Correção da estenose: implante do enxerto SID (seta). 


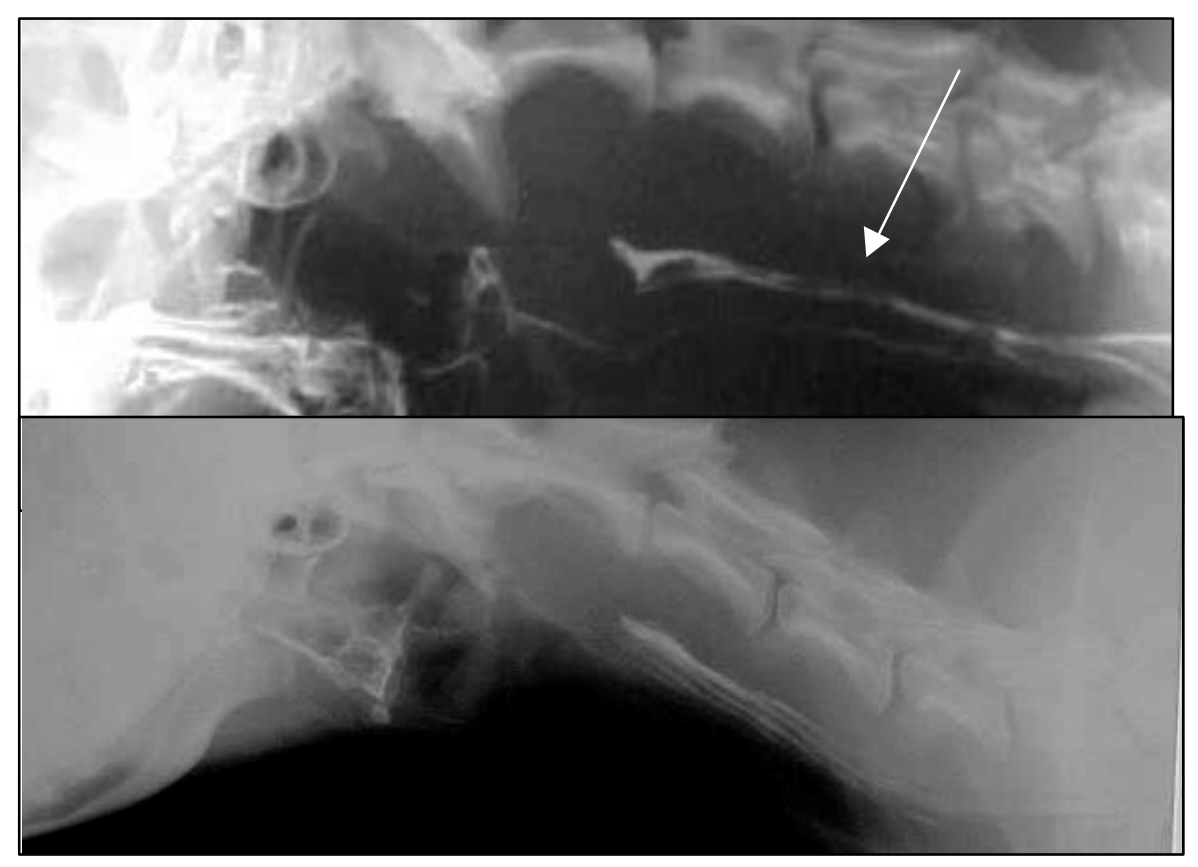

FIGURA 4 - Esofagograma: esôfago com estenose (acima) e após a correção (abaixo).

Logo em seguida ao exame radiológico, os animais foram submetidos a eutanásia. Os esôfagos foram analisados e submetidos a estudo histopatológico (regeneração tecidual, vascularização, incorporação do enxerto, fibrose, inflamação e colágeno).

A regeneração epitelial, neovascularização, fibrose, inflamação e incorporação do enxerto foram analisadas na coloração hematoxilina-eosina, enquanto que o colágeno pelo SirusRed. Avaliou-se neste último a presença de colágeno tipo I - maduro e colágeno tipo III imaturo. A coloração Sirus-Red foi também utilizada para identificar a presença e a disposição da fibras musculares. As imagens foram capturadas numa câmera Sony CCD 101 e transmitidas para um monitor colorido Trinitron Sony. Utilizou-se o aplicativo Image-Pro ${ }^{\circledR}$ Plus versão 4.5 para Windows ${ }^{\circledR}$ da Media Cibernetics num computador da linha Pentium. Estabeleu-se a porcentagem de colágeno em 3 campos com aumento de 200 vezes, obtendo-se a média em cada lâmina examinada.

\section{Alimentação e pós-operatório}

Ao tempo da estenose, iniciou-se a alimentação com 24 horas de pós-operatório com uma dieta pastosa com o alimento Sustagem? que foi mantido durante os 3 meses deste primeiro período pós-operatório. Após a correção com SID, iniciou-se também a alimentação com 24 horas de pós-operatório com dieta idêntica a acima descrita. Este alimento foi instituído durante 5 dias, quando então os cães passaram a ser alimentados com a ração tradicional. Foi administrado antibiótico em caráter profilático (Cefazolina 500mg endovenosa), uma dose junto à indução da anestesia. 


\section{Análise das medidas radiológicas}

Dois animais foram excluídos da análise radiológica por problemas técnicos com a execução do exame.

Obteve-se a média aritmética geral dos valores da largura proximal e média (individualmente) nos tempos "com estenose" e "pós-correção" (e seus respectivos desvios padrão) dos 10 cães. Foi também calculada a média aritmética da somatória da medida proximal e média de cada cão com estenose e após a correção. Com base nestes valores, calculou-se a porcentagem de acréscimo sobre esta média no cão com estenose e póscorreção, ou seja, a porcentagem de acréscimo médio na largura esofágica de cada animal. Adotou-se o teste não paramétrico de Wilcoxon ${ }^{31}$ como avaliação estatística destes valores. Considerou-se $\mathrm{p}<0,05$ como significante.

\section{Resultados}

Não houve infecção ou fístula. Os cães alimentaram-se precocemente e não perderam massa ponderal.

Quanto às análises da largura esofágica, observou-se um acréscimo médio de $0,19 \mathrm{~cm}$ na medida proximal e de $0,13 \mathrm{~cm}$ na porção média do esôfago cervical (considerando-se os 10 cães) (Tabela 1). Em relação à porcentagem sobre a largura esofágica, evidenciou-se acréscimo em 7 (70\%) animais. Um dos cães não sofreu alteração e os 2 restantes apresentaram redução da largura esofágica mesmo após a correção. Houve acréscimo de 43\% em média na largura esofágica dentre os 7 cães que evidenciaram aumento da largura. Considerando-se todos os 10 animais, este acréscimo foi em média de 28,3\% (Tabela 2; Figura 5).

TABELA 1 - Acréscimo médio na largura esofágica (porções proximal e média do esôfago cervical).

\begin{tabular}{c|cccc}
\hline $\begin{array}{c}\text { Largura } \\
\text { esofágica }(\mathbf{c m})\end{array}$ & Momento & $\begin{array}{c}\text { Média (cm)? } \\
\text { Desvio padrão }\end{array}$ & $\begin{array}{c}\text { Acréscimo } \\
\text { Médio (cm) }\end{array}$ & $\begin{array}{c}\text { Significância } \\
(\boldsymbol{p})\end{array}$ \\
\hline \multirow{2}{*}{ Proximal } & $\begin{array}{c}\text { Estenose } \\
\text { Pós-correção }\end{array}$ & $\begin{array}{l}0,76 ? \\
0,95 ? 0,22\end{array}$ & 0,19 & $P=0,0209$ \\
\hline \multirow{3}{*}{ Porção Média } & Estenose & $0,63 ? 0,17$ & 0,13 & $P=0,1073$ \\
& Pós-correção & $0,76 ? 0,13$ & & \\
\hline
\end{tabular}


TABELA 2 - Acréscimo percentual médio da largura esofágica ( $\mathrm{p}=0,2135)$.

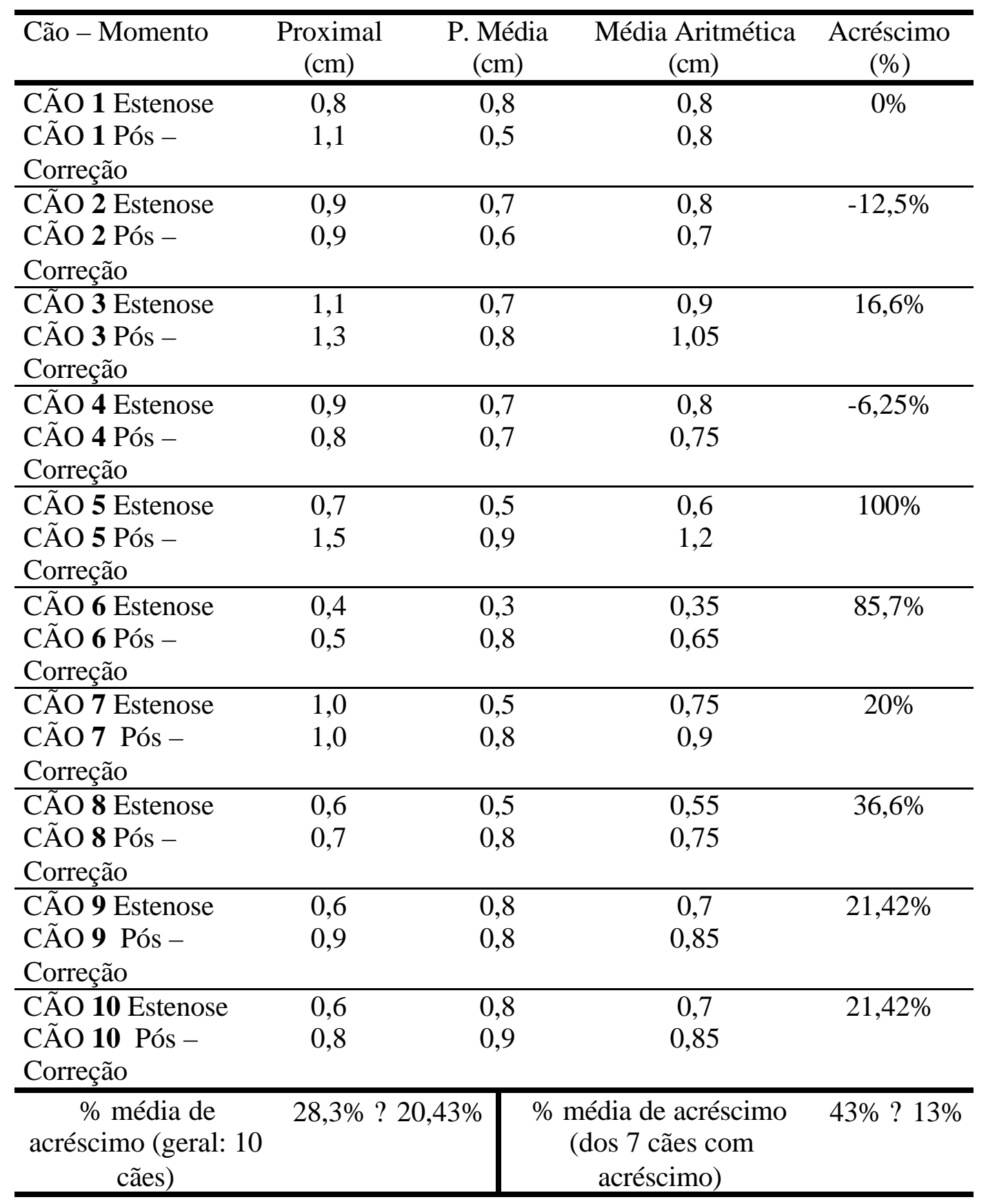




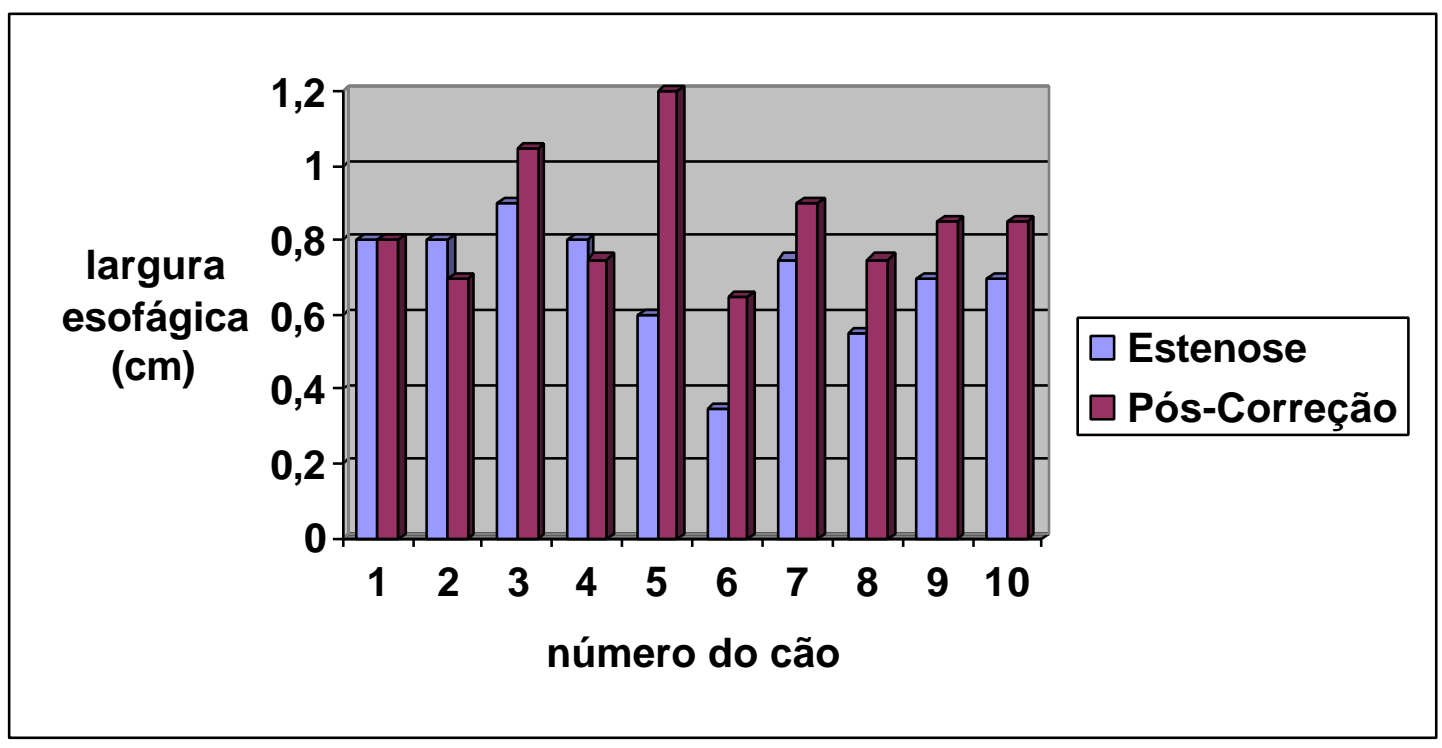

FIGURA 5 - Demonstração gráfica da largura esofágica aos tempos estenose e póscorreção.

O aspecto macroscópico demonstrou o local do enxerto já cicatrizado, com cobertura completa da camada mucosa. Externamente não foi possível identificar cicatriz na camada muscular (Figura 6).

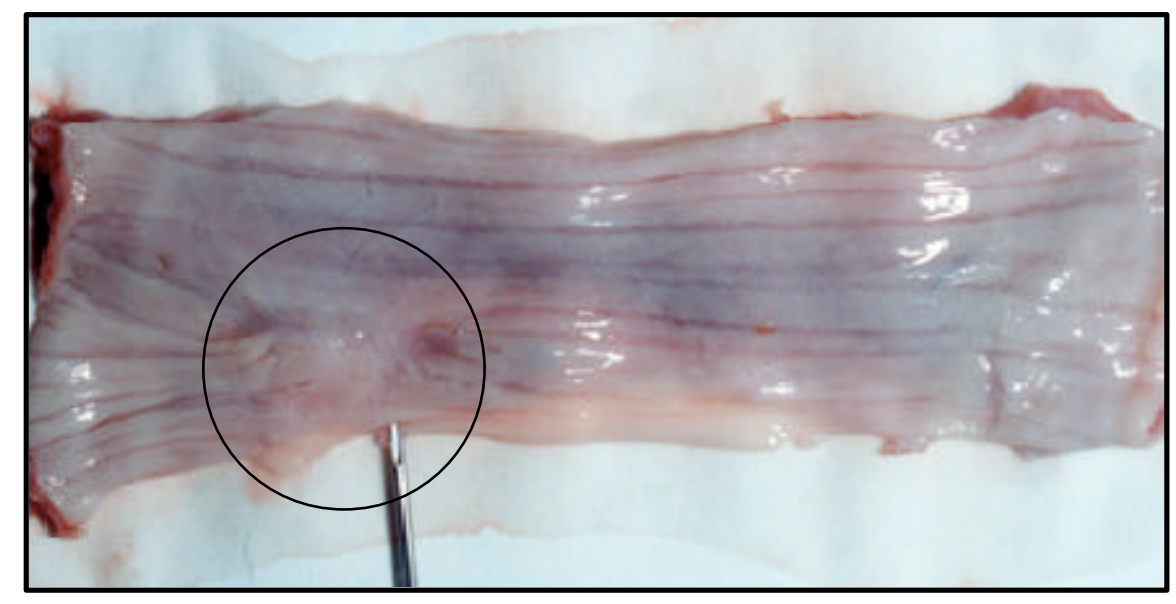

FIGURA 6 - Sítio de implante: aspecto macroscópico da peça cirúrgica aos 60 dias.

O estudo anátomo-patológico pela coloração HE revelou reepitelização total da mucosa em $66 \%$ dos cães e parcial (80\% de reepitelização) em 44\% (Figura 7). A incorporação do enxerto foi completa em $75 \%$ dos casos. Quanto a proliferação fibroblástica (fibrose), esta foi intensa em $75 \%$ dos cães e moderada nos demais $25 \%$. Em relação à proliferação neovascular, esta foi moderada em $66 \%$ dos casos e, discreta, em 44\%. A resposta inflamatória aguda foi ausente na maioria dos cães (66\%); discreta em 25\% (média de 14 
células por campo) e moderada em 1 animal (80 células por campo). Já a resposta inflamatória crônica foi mais proeminente, uma vez que houve inflamação discreta em $91 \%$ dos cães (média de 16 células por campo) e intensa em 1 animal (120 células por campo) (Tabela 3). Observou-se com a coloração Sirus-Red a presença de novas fibras musculares em todas as peças esofágicas. Tanto a camada muscular longitudinal quanto a circular puderam ser identificadas. Estas fibras apresentaram-se de maneira menos organizada que as fibras adjacentes (esôfago normal), mas as camadas eram semelhantes em espessura (Figura 8).

TABELA 3 - Análise histológica dos sítios de implante do enxerto no esôfago.

\begin{tabular}{cccccccc}
\hline Identificação & $\begin{array}{c}\text { Reepiteliza- } \\
\text { ção mucosa }\end{array}$ & Fibrose & $\begin{array}{c}\text { Incorporação } \\
\text { da SID }\end{array}$ & $\begin{array}{c}\text { Inflamação } \\
\text { crônica }- \\
\text { CGA }\end{array}$ & $\begin{array}{c}\text { Inflamação } \\
\text { aguda- } \\
\text { CGA** }\end{array}$ & $\begin{array}{c}\text { Granulomas } \\
\text { /corpo } \\
\text { estranho }\end{array}$ & Neovasos \\
\hline Cão 1 & Parcial 80\% & Moderada & Parcial & 38 & 24 & Raros & Discreto \\
Cão 2 & Total & Intensa & Total & 10 & 0 & Raros & Moderado \\
Cão 3 & Total & Intensa & Total & 12 & 0 & Raros & Moderado \\
Cão 4 & Parcial 80\% & Intensa & Parcial & 25 & 12 & Raros & Discreto \\
Cão 5 & Total & Moderada & Total & 12 & 0 & Raros & Moderado \\
Cão 6 & Total & Intensa & Total & 10 & 0 & Raros & Moderado \\
Cão 7 & Parcial 80\% & Intensa & Total & 22 & 18 & Raros & Discreto \\
Cão 8 & Total & Intensa & Total & 14 & 0 & Raros & Moderado \\
Cão 9 & Total & Intensa & Total & 12 & 0 & Raros & Moderado \\
Cão 10 & Total & Intensa & Total & 10 & 0 & Raros & Moderado \\
Cão 11 & Total & Intensa & Total & 14 & 0 & Raros & Moderado \\
Cão 12 & Parcial 80\% & Moderada & Parcial & 120 & 80 & Raros & Discreto \\
\hline
\end{tabular}

**CGA: Campo de Grande Aumento: média de células por campo de grande aumento ao microscópio. Média de 5 campos analisados por corte histológico.

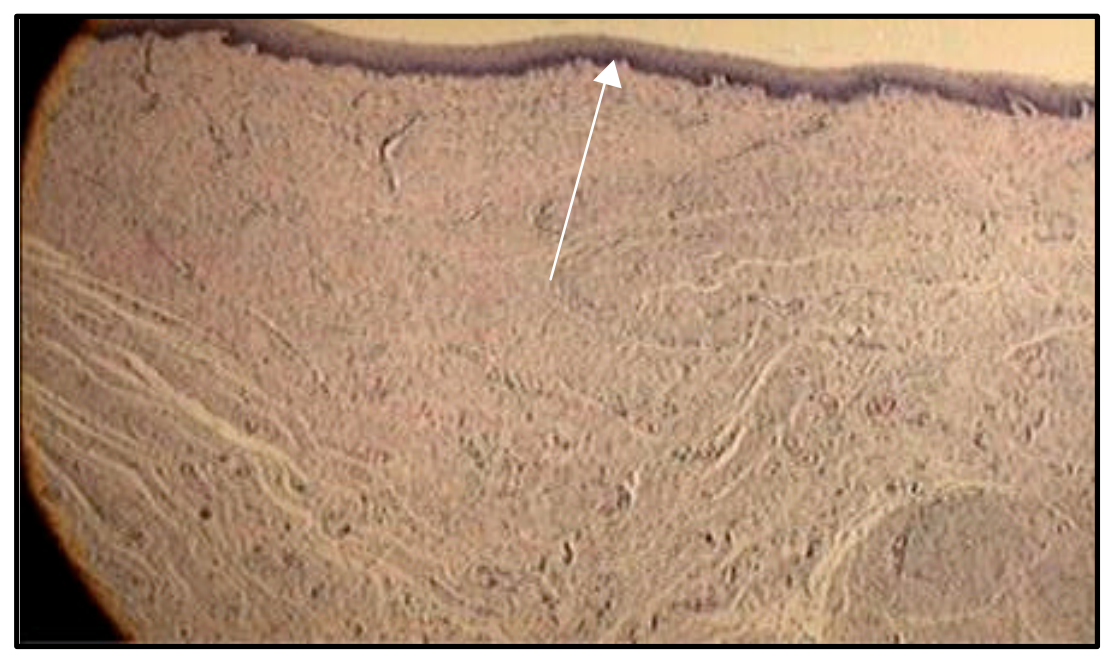


FIGURA 7 - Aspecto histológico do esôfago: sítio do enxerto, apresentando reepitelização total (seta).

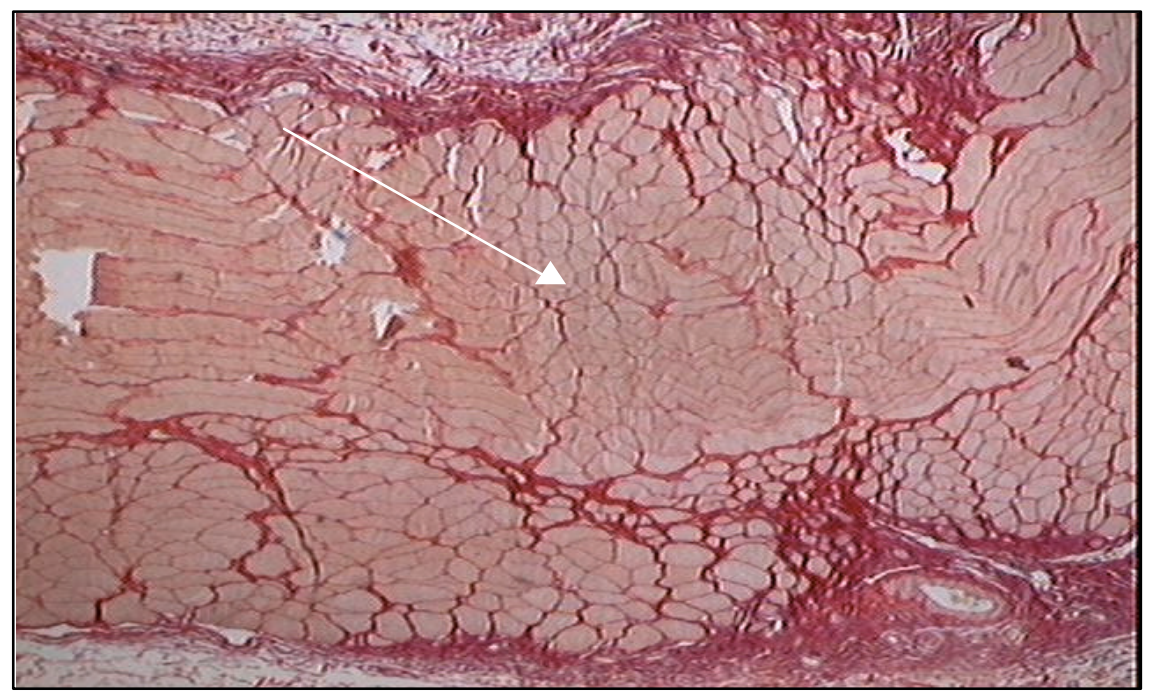

FIGURA 8 - tecido muscular formado aos 60 dias.

A quantificação do colágeno pela coloração Sirus-red demonstrou haver maior porcentagem de colágeno maduro (tipo I) em relação ao imaturo (tipo III) em 100\% dos cães. A porcentagem média de colágeno maduro foi de 59,89\%. A de colágeno imaturo, 40.09\% (Tabela 4). 
TABELA 4 - Relação percentual média de colágeno maturo X colágeno imaturo.

\begin{tabular}{ccc}
\hline Cão & Colágeno Maturo (\%) & Colágeno Imaturo (\%) \\
\hline $\mathbf{1}$ & 54,35 & 45,57 \\
$\mathbf{2}$ & 63,98 & 36,01 \\
$\mathbf{3}$ & 63,46 & 36,53 \\
$\mathbf{4}$ & 62,37 & 37,61 \\
$\mathbf{5}$ & 59,88 & 37,61 \\
$\mathbf{6}$ & 64,37 & 35,61 \\
$\mathbf{7}$ & 67,80 & 32,18 \\
$\mathbf{8}$ & 56,91 & 43,07 \\
$\mathbf{9}$ & 56,13 & 43,85 \\
$\mathbf{1 0}$ & 50,23 & 49,75 \\
$\mathbf{1 1}$ & 69,48 & 30,50 \\
$\mathbf{1 2}$ & 49,69 & 50,29 \\
\hline Média & 59,89 & 40,09 \\
Desvio Padrão & 6,47 & 6,47 \\
\hline
\end{tabular}

\section{Discussão}

Grandes lesões esofágicas com significativa perda tecidual são sempre relevantes e de difícil tratamento ${ }^{1,9}$. Requerem técnicas inovadoras e apresentam elevada morbidade. ${ }^{3,4,7,8}$. Mesmo com o avanço da terapia intensiva e dos antibióticos, que diminuíram os índices de mortalidade, os custos e a morbidade continuam altos. Uma das complicações das lesões do esôfago é a própria estenose do órgão.

A estenose esofágica é uma entidade cujo manejo muitas vezes é cirúrgico. Os tratamentos propostos até o momento variam conforme o agente causador da doença e obviamente, com a extensão da lesão.

A variedade de condutas demonstra a dificuldade em se desenvolver técnicas que sejam eficientes o bastante a ponto de haver um consenso frente à terapêutica adequada. Cerulli e cols. , numa extensa revisão a respeito das estenoses esofágicas, relataram que a principal causa é a péptica. Para seu tratamento, propõe o uso de dilatadores e "stents" endoscópicos como a melhor opção ${ }^{1}$.

Outros autores relatam sobre técnicas que fazem uso de segmentos pediculados tanto de cólon transverso quanto de jejuno. Othersen e cols. , ao utilizar enxerto de cólon transverso a fim de aumentar o calibre esofágico, puderam observar dentro de um seguimento de 10 anos de seus pacientes, ótimos resultados, com poucas complicações ${ }^{10}$. Chana e cols. 
revelaram que sua técnica de reconstrução esofágica microcirúrgica com "flaps" pediculados de jejuno apresentou-se sempre benéfica para grupos de pacientes considerados de difícil manejo ${ }^{11}$.

Young e col. , em uma extensa revisão sobre reconstrução esofágica através de substituição do órgão por estômago, cólon ou jejuno, concluíram que houve melhora funcional na maioria dos pacientes, e que isto pode ser obtido com baixa morbidade e aceitável mortalidade ${ }^{12}$.

Baseados nas experiências prévias, nossas ${ }^{29}$ e de Badylak ${ }^{28}$, idealizamos a técnica de correção de estenose esofágica utilizando o enxerto de Submucosa Intestinal. Estes autores viabilizaram o seu emprego com finalidade de reparar lesões com perda parcial de tecido esofágico em cães. Observaram uma reepitelização completa da camada mucosa e incompleta da muscular; presença de neovasos, discreta resposta inflamatória, incorporação completa do enxerto, presença significativa de colágeno e excelente resposta à tensiometria (resistência) das peças cirúrgicas. Além disso, verificaram ausência de fístula e estenose pós-operatórias.

O enxerto que empregamos no reparo de lesões esofágicas cervicais pode ser obtido facilmente, rapidamente e com baixo custo. Além disso, sabe-se que a SID proporciona um reparo efetivo no sítio da lesão e, ao mesmo tempo, serve como um molde de matriz colágena através do qual o tecido original cresce e se regenera, tomando seu lugar ${ }^{18-20}$. Este enxerto é rapidamente reabsorvido (aproximadamente 2 meses).

De acordo com o que foi exposto até então na literatura, não nos dispusemos a substituir a totalidade da circunferência do esôfago. Segundo os autores, quando executado este procedimento, há elevada morbidade e mortalidade decorrentes de elevado grau de estenose instalado ${ }^{28}$. Observou-se que a patência do local substituído pelo enxerto deve-se à pressão intra-luminal do órgão. A comprovação desta característica é observada quando se propõe substituição total da circunferência de vasos sangüíneos. Nestas estruturas não ocorre estenose. Já a substituição de segmentos completos de esôfago, ureter e intestino - órgãos que não possuem pressões endolumiais satisfatórias, observa-se tal complicação ${ }^{28}$.

A histologia por HE evidenciou proliferação fibroblástica intensa em $75 \%$ dos casos ${ }^{21}$. Isso representa que ocorreu excelente cicatrização do local do enxerto, conferindo resistência ao tecido. Houve reepitelização completa da mucosa em $66 \%$ dos casos ${ }^{28}$. Evidenciou-se formação de um novo tecido muscular em todos os animais. $\mathrm{O}$ mesmo foi relatado por Badylak $^{28}$. Segundo este autor, há uma organização relativa da camada muscular quando a SID é implantada no esôfago. Nenhum trabalho demonstrou a eficácia da contratilidade de tais fibras musculares. Quanto a neovascularização, esta foi predominantemente moderada $1,5,28$. Isto foi considerado bom para um órgão que certamente apresentou desvascularização importante ao ser manuseado e é, naturalmente, pouco angiogênico. A incorporação do enxerto foi completa em $75 \%$ dos casos e a resposta inflamatória foi discreta na maioria dos animais $2,21,22,24$. Estes aspectos confirmam o que é extensamente relatado na literatura sobre as características da SID.

Os resultados verificados na coloração Sirus-red vieram a confirmar a satisfatória resposta cicatricial inerente ao enxerto. Aos 60 dias de pós-operatório, a porcentagem de colágeno maduro foi de 59,89\% e de colágeno imaturo, 40,09\%, valores estes considerados satisfatórios para o período de observação proposto. Certamente este colágeno foi o responsável pela boa resposta tensiométrica do enxerto, conferindo resistência ao tecido. 
Com características de não haver rejeição ou infecção e de neovascularização ${ }^{13,20-28}$, a matriz colágena extracelular se encaixa como uma base propícia para uma regeneração tecidual ideal, com baixíssimo grau de retração tecidual e sem o aparecimento de fístulas. Acreditamos que a eficácia da SID na correção de estenose esofágica seja certamente uma realidade. Para que induzíssemos a estenose e reconstruíssemos o esôfago, realizamos duas ressecções teciduais, com perda considerável de substância do órgão. Mesmo com pouco tecido esofágico restante, houve recuperação do lúmem do esôfago após o implante da SID. Devemos lembrar que nossos resultados não foram apenas satisfatórios em termos numéricos (acréscimo médio de $43 \%$ da largura esofágica), pois é também válido de nota que não dispúnhamos da possibilidade de alimentação parenteral, da utilização de sondas, estomias e outros cuidados inerentes a este tipo de procedimento caso tivesse sido realizado no homem. Por fim, o tempo cirúrgico utilizado para o reparo propriamente dito foi aproximadamente de 25 minutos, uma grande vantagem se comparado aos outros procedimentos de reconstrução cirúrgica descritos na literatura.

\section{Conclusão}

A SID é eficaz quando implantada como substituto tecidual no esôfago canino, com o intuito de corrigir lesões estenosantes induzidas, tornando-se assim uma possível alternativa.

\section{Referências}

1. Cerulli MA, Talavera F, Bank S. Esophageal stricture. Available from URL: http://www.emedicine.com/med/topic744.htm.

2. Banecko RM, Shields TW, Esophageal trauma. Gen Thorac Surg 1994, 55:1514-25.

3. Kajitani M, Wadia Y, Hinds M, Teach J, Swartz K, Gregory K. Successful repair of esophageal injury using a elastin based biomaterial patch. Asaio J 2001; 4:342-5.

4. Grillo HG, Wilkins EW. Esophageal repair following late diagnosis of intrathoracic perforation. Ann Thorac Surg 1975; 29: 387-99.

5. Thal AP, Hatafuku T, Kurtzman R. New operation for distal esophageal stricture. Arch Surg 1965; 90:464-72.

6. Urschel Jr HC, Razzuk MA, Wood RE. Improved management of esophageal perforations. Thorax 1977; 32:241-49.

7. Pass LJ, LeNarz LA, Schreiber JT. Management of esophageal gunshot wounds. Ann Thorac Surg 1987; 44:253-6.

8. Popovski J. Perforation of the esophagus by gunshot wounds. J Trauma 1984; 24:337-9.

9. DeMeester TR. Perforation of the esophagus (editorial). Ann Thorac Surg 1986.

10. Othersen HB Jr, Smith CD. Colon-patch esophagoplasty in children: an alternative to esophageal replacement. J Pediatr Surg 1986; 21:224.

11. Chana JS, Chen HC, Sharma R, Gedebou TM, Feng GM. Microsurgical reconstruction of the esophagus using supercharged pedicle jejunum flaps: special indications and pitfalls. Plast Reconstr Surg 2002; 1:110(3):742-8.

12. Young MM, Deschamps C, Trastek VF, Allen MS, Miller DL, Scheleck CD. Esophageal reconstruction for benign disease: early morbity, mortality and functional results. Ann Thorac Surg 2000; 70(5):1651-5. 
13. Roeder R, Wolf J, Lianakis N. Compliance, elastic modulus, and burst pressure of small-intestine submucosa (SIS), small-diameter vascular grafts. J Biomed Mater Res 1999; 47: 65.

14. Vaught JD, Kropp BP, Sawyer BD, Rippy MK, Badylak SF, Shannon HE, Thor, KB. Detrusor regeneration in the rat using porcine small intestine submucosal grafts: functional inervation and receptor expression. J Urol 1996; 155(1):374-8.

15. Badylak SF, Kropp B, McPherson T. Small intestinal submucosa: a rapidly resorbed bioscaffold for argumentation cytoplasty in a dog model. Tissue Eng 1998; 4:379.

16. Greca FH, Biondo-Simões MLP, Santos EA, Chin EWK, Ioshii SO. Retalho de Submucosa de Intestino Delgado Autólogo para Aumento da Capacidade da Bexiga: Estudo Experimental em Cães. Revista do Colégio Brasileiro de Cirurgiões 2002; 29(5):294-9.

17. Prevel C, Eppley B, Summerlin DJ, Jackson JR, McCarty M, Badylak SF. Small intestinal submucosa: utilization for repair of rodent abdominal wall defects. Ann Plastic Surg 1995; 34(4):37480 .

18. Peel SAF, Chen H, Renlund R, Badylak SF, Kandel RA. Formation of a SIS-cartilage composite graft in vitro and its use in the repair of articular cartilage defects. Tissue Eng 1998; 4(2):143-55.

19. Hodde JP, Badylak SF, Brightman AO, Voyti-Harbin SL. Glycosaminoglycan content of small intestine submucosa: A bioscaffold for tissue replacement. Tissue Eng 1996; 2:209-17.

20. Hodde JP, McPherson TB, Savaiano JK, Badylak SF. Vascular endotelial growth factor (VEGF) in SIS. SIS Symp1998; p.92.

21. Liang, HA. Determination of Platelet-Derivad Growth Factor in Small Intestinal Submucosa. SIS Simp.1998; p93.

22. Voytik-Harbin SL, Brightman AO, Kraine M, Waisner B, Badylak, SL. Identification of extractable growth factors from small intestinal submucosa. J Cel Bio 1997; 67:478-91.

23. McPherson TB, Badylak SF. Characterization of fibronectin derived from porcine small intestinal submucosa. Tissue Engineering 1998; 4:75-83.

24. McPherson TB, Badylak SF, Hogenesch, H. Efect of local response to xenogeneic ECM on systemic immunity. SIS Symp1998; p34.

25. Metzger DW, McPhersonTB, Merrill LA, Moyad TF, Badylak SF. Immune responses to xenogeneic SIS Implants. SIS Symp1998; p.33.

26. Allman AJ, McPherson TB, Timothy B, Badylak SF, Merril LC, Kallakury B, Sherran C, Raeder RH, Metzger DW. Xenogeneic extracellular matrix grafts elicit a th-2-restricted immune response. Transplantation 2001; 71(11):1631-40.

27. Badylak SF, Coffey AC, Lantz GC. Comparison of resistance to infection of small intestinal submucosa arterial autografts versus polytetrafluoroethilene arterial prostheses in a dog model. J Vasc Surg 1994; 19:465.

28. Badylak SF, Meurlin S, Chen M. Resorbable bioscaffold for esophageal repair in a dog model. J Pediatr Surg 2000; 35(7):1097-103.

29. Souza Filho ZA, Ioshii SO, Greca FH, Biondo-Simões MLP, Duda JR: Emprego da submucosa de intestino delgado porcina no reparo de lesões do esôfago cervical: estudo experimental em cães. Acta Cir Bras 2003; 18(3):224-31.

30. Badylak SF, Lantz GC, Coffey AC, Geddes LA. Small intestinal submucosa as a large diameter vascular graft in the dog. J Surg Res 1989; 47:74-98.

31. Siegel S. Nonparametric statistics. New York: McGraw-Hill Book Company; 1956. 


\section{Agradecimentos}

Agradecemos ao Dr. Indalécio Sutil, médico veterinário responsável pelo Biotério da Pontifícia Universidade Católica do Paraná, por sua participação/colaboração na avaliação e cuidados com os animais utilizados no presente trabalho.

Os mais sinceros agradecimentos a Prof ${ }^{\mathrm{a}}$. Assistente Nível III de Diagnóstico por Imagem da Medicina Veterinária da PUC-PR e UFPR por contribuir de forma decisiva para análise de dados pertinentes ao trabalho e também, a Bioestatística e Professora do Centro de Ciências Biológicas e da Saúde da PUC-PR, Márcia Olandoski, pelo estudo estatístico desta pesquisa.

Correspondência:

Zacarias Alves de Souza Filho

Rua Padre Agostinho, 1923/1901

80710-000 Curitiba - PR

Tel: (41)336-3445

gcravo@voe.com.br

Recebimento: 05/03/2004

Revisão: 12/04/2004

Aprovação: 09/05/2004

Conflito de interesse: nenhum

Fonte de financiamento: nenhuma

Como citar este artigo:

Souza Filho ZA, Greca FH, Duda JR, Cravo GZ, Ioshii SO. Emprego da submucosa de intestino delgado na correção de estenose esofágica em cães. Acta Cir Bras [serial online] 2004 Jul-Ag;19(4). Disponível em URL: http://www.scielo.br/acb [também em CD-ROM]. 